Abstracted/indexed in Academic Search Complete, Asia Journals Online, Bangladesh Journals Online, Biological Abstracts, BIOSIS Previews, CAB

Abstracts, Current Abstracts, Directory of Open Access Journals, EMBASE/Excerpta Medica, Google Scholar, HINARI (WHO), International

Pharmaceutical Abstracts, Open J-gate, Science Citation Index Expanded, SCOPUS and Social Sciences Citation Index;

\title{
Separation and purification of low-molecular-weight chondroitin sulfates and their anti-oxidant properties
}

\author{
Jinpeng Wang,,2,3, Lian Zhang1,2 and Zhengyu Jin ${ }^{1,2}$ \\ ${ }^{1}$ State Key Laboratory of Food Science and Technology, ${ }^{2}$ School of Food Science and Technology, ${ }^{3}$ Synergetic \\ Innovation Center of Food Safety and Nutrition, Jiangnan University, Wuxi, Jiangsu 214 122, China.
}

\begin{tabular}{|c|c|}
\hline \multicolumn{2}{|l|}{ Article Info } \\
\hline Received: & 16 January 2016 \\
\hline Accepted: & 22 February 2016 \\
\hline Available Online: & 4 March 2016 \\
\hline \multicolumn{2}{|c|}{ DOI: 10.3329/bjp.v11iS1.26414 } \\
\hline \multicolumn{2}{|c|}{$\begin{array}{l}\text { Cite this article: } \\
\text { Wang J, Zhang L, Zhengyu J. Separa- } \\
\text { tion and purification of low-molecular } \\
\text {-weight chondroitin sulfates and their } \\
\text { anti-oxidant properties. Bangladesh J } \\
\text { Pharmacol. 2016; 11: S61-S67. }\end{array}$} \\
\hline
\end{tabular}

\begin{abstract}
Low-molecular-weight chondroitin sulfate was obtained by degradation of chondroitin sulfate using hyaluronidase. Then, separated with sephadex G25, DEAE-52, and finally purified with AKATA superpeptide separation system and fluorescence-assisted carbohydrate electrophoresis. The main components detected by high performance gel-filtration chromatography were disaccharide, tetrasaccharide, hexasaccharide with molecular weight of 521, 1024 and $1527 \mathrm{Da}$, respectively. The anti-oxidant activity of these three oligosaccharides in vitro showed that the reducing power (maximum value at $10 \mathrm{mg} / \mathrm{mL}$ ) and superoxide anion radical scavenging abilities were increased (maximum value at $4 \mathrm{mg} / \mathrm{mL}$ ) with an increased in their concentration. There were no significant differences of the anti-oxidant properties between those three oligosaccharides.
\end{abstract}

\section{Introduction}

The applications of high-molecular-weight polysaccharides such as glycosaminoglycans are limited by their high molecular weight, high apparent viscosity, poor water solubility, as well as complex structures and conformations. Polysaccharides difficultly pass through organizational barriers to attach onto receptors in the cell interior (Liu et al., 2010). Regarding glycosaminoglycans, their major problem is poor bioavailability. Thus, low-molecular-weight glycosaminoglycans are attracted increasing attention particularly because of their biological activities. The activities of low-molecular-weight hyaluronic acid and heparin were discovered as early as in the 1990s, and extensive pertinent studies followed. However, reports on the activity of chondroitin sulfate are still limited.

Free-radical and active-oxygen generation contribute to tumor development, radiation-caused cancer, cardiovascular and cerebrovascular diseases, ischemia, organ reperfusion, drug poisoning, as well as the aging process (Valko et al., 2007). Glycosaminoglycans, parti- cularly chondroitin-4-sulfate (C4S), possess anti-oxidant activity, ability to inhibit lipid peroxidation (Campo et al., 2008), and neuroprotective properties associated with its anti-oxidant and anti-inflammatory effects (Egea et al., 2010). High- and low-molecular-weight chondroitin sulfate have different or even opposite bioactivities.

Several studies have reported that chondroitin sulfate can relieve the pain and improve the functional status of osteoarthritis patients (McAlindon et al., 2000), and that chondroitin sulfate oligosaccharides generated with mammalian enzymes may possess pro-inflammatory potential (Jobe et al., 2003). Compared with highmolecular-weight chondroitin sulfate, the anti-oxidant properties of low-molecular-weight chondroitin sulfate is unclear, the main reason probably to be lack of separation method for low-molecular-weight chondroitin sulfate. A few literatures provided reference for lowmolecular-weight chondroitin sulfate separation and purification.

The aim of the present study was to find an appropriate 
way to separate and purify molecular-weight chondroitin sulfate and to determine its anti-oxidant activities in vitro.

\section{Materials and Methods \\ Reagents and chemicals}

C4S sodium salt from bovine trachea and bovine testicular hyaluronidase (437 U/mg; EC 3.2.1.35; Type IS) were obtained from Sigma Chemical Co (China). All other chemicals and solvents used were of analytical grade.

\section{Degradation of chondroitin sulfate}

Chondroitin sulfate $(200 \mathrm{mg})$ was digested with bovine testicular hyaluronidase (approximately $1.4 \times 10^{5} \mu \mathrm{L} / \mathrm{L}$ ) in $10 \mathrm{~mL}$ of sodium phosphate buffer $(5 \mathrm{mmol} / \mathrm{L}$, $\mathrm{pH} 5.9)$ at $37^{\circ} \mathrm{C}$ for 22 hours. The reaction was stopped by boiling for $20 \mathrm{~min}$. The sample was centrifuged at 4,000 rpm for $15 \mathrm{~min}$, and the supernatant was recovered.

Separation of chondroitin sulfate degradation products by gel filtration

The supernatant was dialyzed using a dialysis bag (5000 Da) against deionized water for 48 hours, and the deionized water was changed every 4 hours. The sample outside the dialysis bag was concentrated, lyophilized, and stored at $-20^{\circ} \mathrm{C}$. About $1 \mathrm{~mL}$ of lowmolecular-weight chondroitin sulfate $(40 \mathrm{mg} / \mathrm{mL})$ was fractionated on a sephadex G25 column $(1.0 \mathrm{~cm} \times 95$ $\mathrm{cm})$, using deionized water as an eluent at a flow rate of $4 \mathrm{~mL} / \mathrm{min}$. The eluate was automatically collected with a step collector (Redfrac 95) at $4 \mathrm{~mL}$ per tube. Analyses were performed by determining the uronic acid content in the eluate using the carbazole reaction method, and the same fraction was merged. After collection, each fraction was desalted on a sephadex G10 column $(1.0 \mathrm{~cm} \times 95 \mathrm{~cm})$ against deionized water, and then lyophilized to gain samples.

Separation of chondroitin sulfate degradation products by ion exchange

The freeze dried sample was solved into ultrapure water as $10 \mathrm{mg} / \mathrm{mL} .1 \mathrm{~mL}$ of the sample was injected after 2 hours balance of DEAE-52 using ultrapure water. Then grade elution the column using 0-1 mol/L of $\mathrm{NaCl}$ in $75 \mathrm{~min}$, peaks were collected under UV detector at $210 \mathrm{~nm}$.

Purification of low-molecular-weight chondroitin sulfate by preparative electrophoresis

The collected sample from DEAE-52 was then separated by preparative electrophoresis according to the method described by elsewhere (Platzer et al., 1999).

A solution: Boric acid $0.1 \mathrm{~mol} / \mathrm{L}$, Tris $0.1 \mathrm{~mol} / \mathrm{L}$, EDTA
$0.01 \mathrm{~mol} / \mathrm{L}, \mathrm{pH} 8.3$

Spacer gel (5\%): Acrylamide $4.75 \mathrm{~g} / 100 \mathrm{~mL}$, bisacrylamide $0.25 \mathrm{~g} / 100 \mathrm{~mL}$, adjust $\mathrm{pH}$ to 6.3 using $\mathrm{HCl}$. Each $3 \mathrm{~mL}$ of the spacer gel needs $100 \mu \mathrm{L}$ of $10 \%$ ammonium presulfate and $10 \mu \mathrm{L}$ of $\mathrm{N}, \mathrm{N}, \mathrm{N}^{\prime}, \mathrm{N}^{\prime}$-tetramethylethylenediamine (TEMED).

Separation gel (35\%): Acrylamide $31.82 \mathrm{~g} / 100 \mathrm{~mL}$, bisacrylamide $3.18 \mathrm{~g} / 100 \mathrm{~mL}$ and sucrose $15 \mathrm{~g} / 100 \mathrm{~mL}$. Each $10 \mathrm{~mL}$ of the separation gel $200 \mu \mathrm{L}$ of $10 \%$ ammonium presulfate, $20 \mu \mathrm{L}$ of $\mathrm{N}, \mathrm{N}, \mathrm{N}^{\prime}, \mathrm{N}^{\prime}$-tetramethyl-ethylenediamine.

The spacer gel and separation gel were all made up by A solution. Buffer solution: Glycine $1.25 \mathrm{~mol} / \mathrm{L}$, Tris $0.2 \mathrm{~mol} / \mathrm{L}, \mathrm{pH}$ 8.3. Electrophoresis condition: Room temperature, $400 \mathrm{~V}, 4-5$ hours.

The gel was dyed using $0.5 \%$ of toluidine blue dissolved in $2 \%$ of acetic acid solution, and was decolored by $2 \%$ of acetic acid solution. The gel with sample was then cut off and mashed, and put into $1 \mathrm{~mL}$ of $0.1 \mathrm{~mol} / \mathrm{L}$ PBS, shaking for 12 hours, triple repeats were carried out and the liquid supernatant was then desalting using sephadex G10 $(1.6 \times 150 \mathrm{~cm})$.

Purification of low-molecular-weight chondroitin sulfate by superdex peptide separation system

The collect sample was then purified by AKTA purification system with superdex peptide 10/300 GL as separation column. The elution buffer was ultrapure water, flow speed was $0.5 \mathrm{~mL} / \mathrm{min}$. Peaks were collected using UV detector at $210 \mathrm{~nm}$

Purity identification of low-molecular-weight chondroitin sulfate by fluorescent auxiliary sugar electrophoresis

Separated sample was then fluorescence labeled by ANTS (8- naphthylamine-1, 3, 6- trisulfonic acid), the procedure was as following: $60 \mu \mathrm{L}$ of sample was injected into solution containing $3.75 \mu \mathrm{L}$ of ANTS $(0.2$ $\mathrm{mol} / \mathrm{L}$, solvent was $\mathrm{HAc}-\mathrm{H} 2 \mathrm{O}=3: 17)$ and $5 \mu \mathrm{L}$ of DMSO with $1.0 \mathrm{~mol} / \mathrm{L}$ of $\mathrm{NaBH}_{3} \mathrm{CN}$ were dissolved in the solution. The mixtures were blended and set in water bath $\left(40^{\circ} \mathrm{C}\right)$ for 16 hours. Then samples were detected by gel electrophoresis as showed above.

Molecular weight determination of final samples by high-performance gel-filtration chromatography

The molecular weight of the final samples was determined by high-performance gel-filtration chromatography using an Ultrahydrogel ${ }^{\mathrm{TM}}$ linear column $(300 \mathrm{~mm} \times 7.8$ $\mathrm{mm}$ i.d. $\times 2$ ). The other conditions were as follows: Mobile phase, $0.1 \mathrm{~mol} / \mathrm{L} \mathrm{NaNO}_{3}$; flow rate, $0.9 \mathrm{~mL} /$ min; column temperature, $45^{\circ} \mathrm{C}$; and detector, 2410 refractive index detector. The standard curve (log molecular weight vs. retention time) was then drawn. 


\section{Assays for antioxidant properties in vitro}

Estimation of O2-• scavenging activity

About $1 \mathrm{~mL}$ of chondroitin sulfate,low-molecularweight chondroitin sulfate 1 , and low-molecular-weight chondroitin sulfate 2 with different concentrations was added to $2.4 \mathrm{~mL}$ of Tris- $\mathrm{HCl}$ buffer solution ( $\mathrm{pH} \mathrm{8.2),}$ followed by $0.3 \mathrm{~mL}$ of $8 \mathrm{~mol} / \mathrm{L}$ pyrogallol solution. After $5 \mathrm{~min}$, one drop of $10 \mathrm{~mol} / \mathrm{L} \mathrm{HCl}$ solution was added to terminate the reaction and the absorbance was measured at $325 \mathrm{~nm}$. The percentage scavenging effect was calculated as follows:

$\% \mathrm{O}_{2} \cdot \bullet$ scavenged $=\left(A_{0}-A_{325}\right) / A_{0} \times 100$

where $A_{0}$ and $A_{325}$ are the absorbance of deionized water and the sample or ascorbic acid, respectively

\section{Estimation of reducing power}

Each sample in water $(1 \mathrm{~mL})$ was mixed with $2.5 \mathrm{~mL}$ of $200 \mathrm{mmol} / \mathrm{L}$ sodium phosphate buffer ( $\mathrm{pH}$ 6.6) and 2.5 $\mathrm{mL}$ of $1 \%$ potassium ferricyanide. The reaction mixture was incubated at $50^{\circ} \mathrm{C}$ for $20 \mathrm{~min}$, and then $2.5 \mathrm{~mL}$ of $10 \%$ trichloroacetic acid was added. The mixture was centrifuged at 4,000 rpm for $10 \mathrm{~min}$. The upper layer $(2.5 \mathrm{~mL})$ was mixed with $2.5 \mathrm{~mL}$ of deionized water and $0.5 \mathrm{~mL}$ of $0.1 \%$ ferric chloride. The absorbance was measured at $700 \mathrm{~nm}$ against a blank. Ascorbic acid was used as a reference.

\section{Results}

After degradation by hyaluronidase, two chondroitin sulfate degradation products (low-molecular-weight chondroitin sulfate 1 and low-molecular-weight chondroitin sulfate 2) were obtained by separation through dialysis and gel filtration. The low-molecular-weight chondroitin sulfate 1 and low-molecular-weight chondroitin sulfate 2 yields were 22.7 and $44.4 \%$, respectively. Their weight-average molecular weights as determined by high-performance gel-filtration chromatography were 4875 and $1326 \mathrm{Da}$, respectively (Table I). Lowmolecular-weight chondroitin sulfate 1 showed a significantly higher polydispersity index, indicated a wider molecular weight range and a greater polydispersity degree.

The preparation of low-molecular-weight glycosamino- glycans are gaining increased attention. Some types of glycosaminoglycans with low-molecular-weight can effectively inhibit free radicals (Trabucchi et al., 2002), prevent lipid peroxidation (Trommer et al., 2003), and protect against DNA damage (Zhao et al., 2008). However, the anti-oxidant properties of low-molecularweight chondroitin sulfate were unclear. Low-molecular-weight chondroitin sulfate is a kind of acidic oligosaccharide, it can be absorbed by the solid phase in $\mathrm{NH}_{2}$-column, C18-column and silicon column very strongly, that made it very hard to elution sample. Thus, common separation methods, such as high performance liquid chromatography, for oligosaccharide separation are not suitable for low-molecularweight chondroitin sulfate separation. It is necessary to construct a novel and efficiency way for low-molecularweight chondroitin sulfate separation to support further research and to expending the application scope.

Considering the characteristics of low-molecular-weight chondroitin sulfate, the anion exchange chromatograph was selected for further separation. The low-molecularweight chondroitin sulfate 2 was further separated by DEAE-52 (Figure 1).

The molecular weights of those three components were then detected by high-performance gel-filtration chromatography as $521 \mathrm{Da}, 1024 \mathrm{Da}$ and $1527 \mathrm{Da}$, separately (Figure 2). This showed that disaccharide, tetrasaccharide and hexasaccharide were the main components after a series of separation steps. The purity of these three components was then identified by fluorescence assisted carbohydrate electrophoresis. There was only one belt existed showed that the low-molecular-weight chondroitin sulfate has purified and each belt represent one pure component.

Both $\mathrm{O}_{2}^{-} \bullet$ and its derived free radicals are cytotoxic; they can inflict damage to DNA and cell membrane. In this study, the $\mathrm{O}_{2}-\bullet$ scavenging activity of lowmolecular-weight chondroitin sulfate 1 and lowmolecular-weight chondroitin sulfate 2 were shown in Figure 3.

The reducing power is generally associated with the hydrogen-donating ability (Shimada et al., 1992). Many studies have confirmed that the reducing power is an important indicator of anti-oxidant property (Choi et al., 2010), and that because of, the anti-oxidant property and reducing power are concentration dependent. In

Table I

The molecular weight characteristics of chondroitin sulfate degradations by gel filtration column

\begin{tabular}{|lcccc|}
\hline Sample & Molecular weight & Number-average molecular weight & Peak-average molecular weight & Mw/Mn \\
\hline LMWCS1 & 4875 & 2988 & 2712 & 1.632 \\
LMWCS2 & 1326 & 960 & 1078 & 1.381 \\
\hline
\end{tabular}

Low-molecular-weight chondroitin sulfate 1 (LMWCS1); Low-molecular-weight chondroitin sulfate 2 (LMWCS2) 


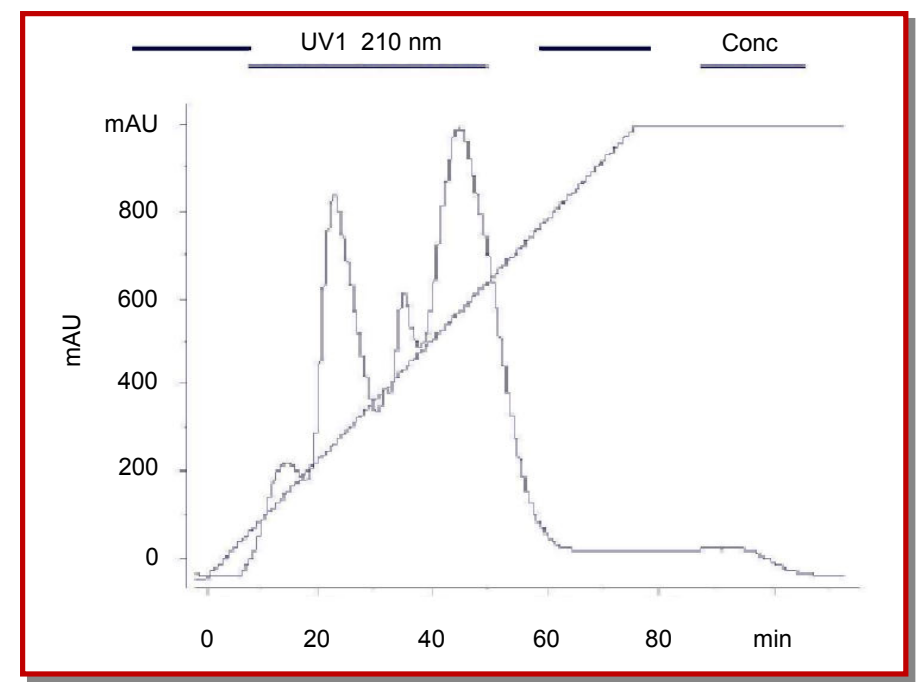

Figure 1: DEAE-52 separation results of low-molecular-weight chondroitin sulfate 2

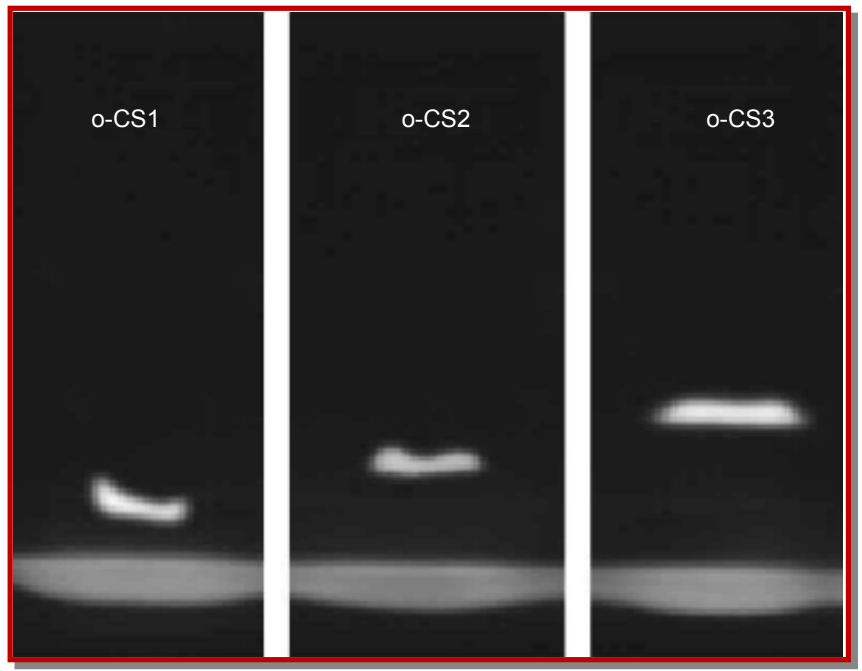

Figure 2: Preparative gel electrophoresis separation results $\mathrm{O}_{2} \bullet \bullet$ is one of the major free radicals in biological systems, and it can produce components showed satisfactory $\mathrm{O}_{2} \cdot \bullet$ scavenging activity, whereas the $\mathrm{O}_{2} \bullet \bullet$ scavenging activity of chondroitin sulfate was almost zero (data not shown). These results further confirmed that the $\mathrm{O}_{2}{ }^{-} \bullet$ scavenging activity of low-molecular-weight chondroitin sulfate increased with an increased in its concentration and reached the maximum value at concentration of $4 \mathrm{mg} / \mathrm{mL}$. There was no significant different of the $\mathrm{O}_{2} \bullet$ scavenging activity between those three components

this study, $\mathrm{Fe}^{3+}$ in the form of ferricyanide was reduced to $\mathrm{Fe}^{2+}$, which then reacted to produce Perl Prussian Queensland, which has a maximum absorbance at 700 $\mathrm{nm}$. The absorbance strength was proportional to the $\mathrm{Fe}^{2+}$ concentration, the stronger absorbance value at 700 $\mathrm{nm}$ reflected higher anti-oxidant property. Analysis results of the absorbance strength of low-molecularweight chondroitin sulfate in the ferricyanide system (Figure 4) revealed that the reducing power of lowmolecular-weight chondroitin sulfate increased with an increased in its concentration and reached the maximum value at $10 \mathrm{mg} / \mathrm{mL}$.

\section{Discussion}

The above separation results showed that acidic oligo- saccharide can be separated efficiently by combination of ion exchange and gel chromatograph. This property was similar as protein, which always be separated by combination of ion exchange and gel chromatograph. The probably reason may be the similar ionization electron ability for acid oligosaccharide as that of protein. Moreover, this study also provided a good reference for low-molecular-weight chondroitin sulfate separation in a large scale. From above results, vitro antioxidant tests revealed that the free-radical scavenging activities, reducing power of low-molecular -weight chondroitin sulfate were higher than those of chondroitin sulfate. Very few related references support this phenomenon. Some researchers have suggested that the carbonyl groups, charged groups, as well as, sulfation position and degree in the structure of chondroitin sulfate and low-molecular-weight chon- 


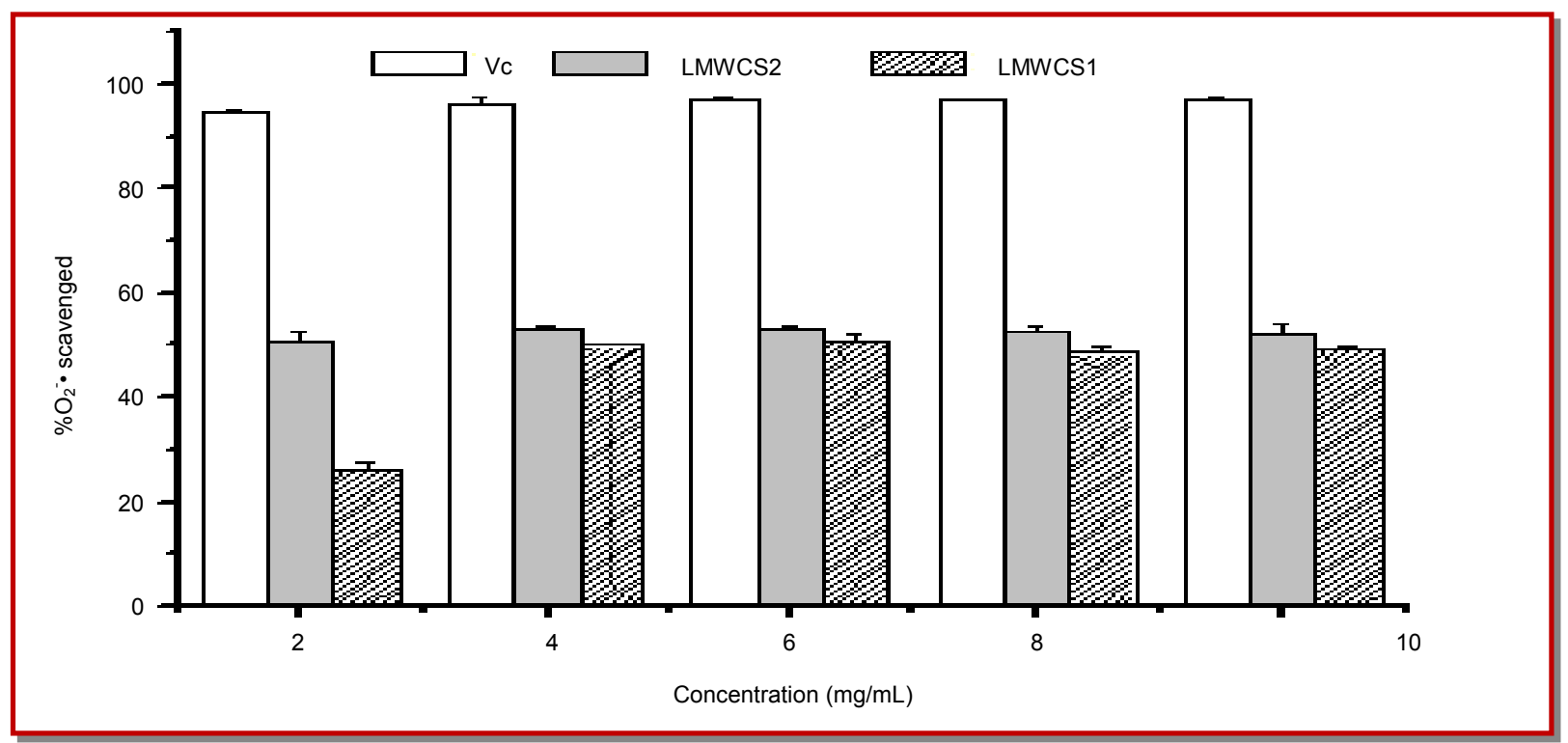

Figure 3: Scavenging activities of chondroitin sulfate (CS), low-molecular-weight chondroitin sulfate 1 (LMWCS1 ) and lowmolecular-weight chondroitin sulfate2 (LMWCS2) on superoxide radical. The ascorbic acid (Vc) was used as a reference. Each value is the mean $\pm \mathrm{SD}$ of triplicate measurements

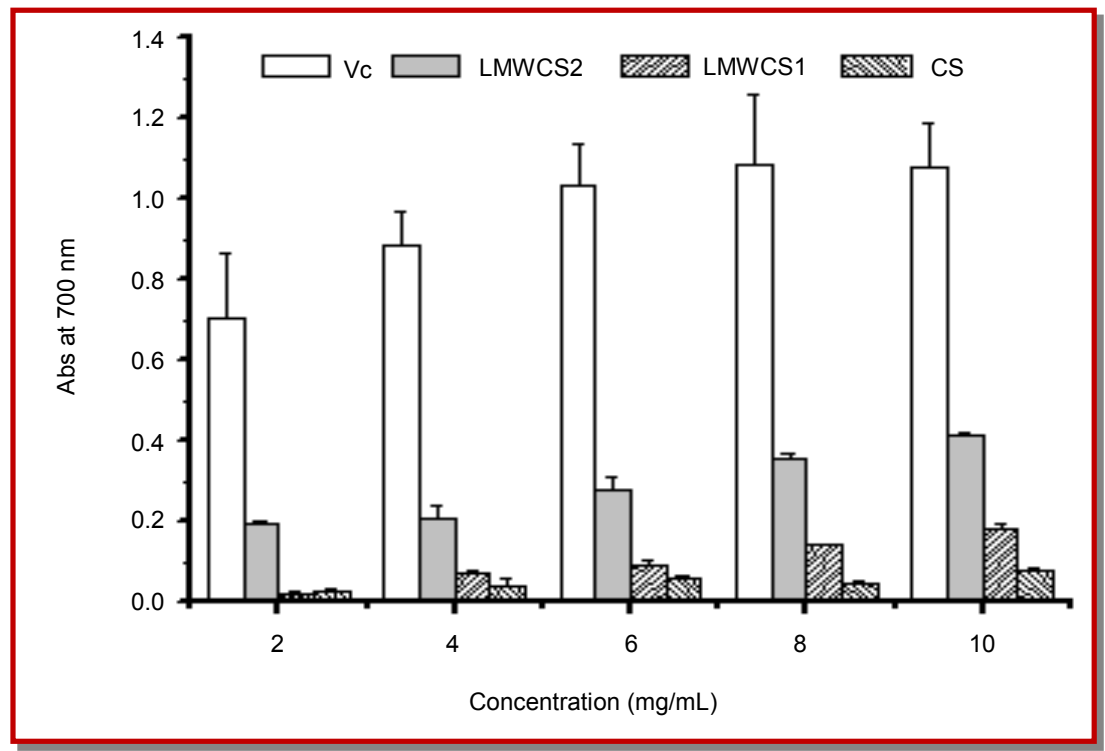

Figure 4: The reducing powers of chondroitin sulfate (CS), low-molecular-weight chondroitin sulfate 1 (LMWCS1) and lowmolecular-weight chondroitin sulfate 2 (LMWCS2). The ascorbic acid (Vc) was used as a reference. Each value is the mean \pm SD of triplicate measurements

droitin sulfate may play roles in their anti-oxidant properties (Duh, 1998; Campo, et al., 2004a; Campo, et al., 2004b; Campo, et al., 2003; Mark et al.,1990). Some others researchers reported that mole-cular weight of sulfated polysaccharides has some relationship with their activity. In mammalian GAGs, enzymatically digested hyaluronate showed higher radical scavenging activity than intact HA (Kim et al., 2008), and HA polysaccharides with different branching degrees of exhibit different biological activities (Stern, 2003). Lowmolecular-weight (3-10 kDa) disaccharides have unique biological activities compared with high-molecularweight (6-20 kDa) ones, which can inhibit the anchorage-dependent growth of tumor cells. Regarding sulfated polysaccharides, Nishino et al., reported that high-molecular-weight fucan (27-58 kDa) had higher anticoagulant activity than low-molecular-weight fucan (about $10 \mathrm{kDa}$ ) (Nishino et al., 1991). This finding could be attributed to the fact that linear sulfated fucan required significantly longer chains than mammalian GAGs to achieve anticoagulant activity(Pomin et al., 2005). The antiviral activity is also related to the molecular weight, which was increased with an increased in molecular weight (Witvrouw et al., 1997). However, few studies have reported on the relationship between anti-oxidant properties and molecular weight. 
We speculated that the anti-oxidant properties of CS might be related to its molecular weight to some extent, i.e., short chains may be required to achieve antioxidant property.

Interestingly, our results showed that low-molecularweight chondroitin sulfate had high solubility (data not shown) and can be quickly dissolved in water. However, the chondroitin sulfate polymer needed to be strongly stirred to be dissolved. We speculated that the extent of biological absorption of low-molecular-weight chondroitin sulfate was superior to that of highmolecular-weight chondroitin sulfate in vivo because of the good water solubility and small size of lowmolecular-weight chondroitin sulfate.

The anti-oxidant properties of low-molecular-weight chondroitin sulfate can serve as a reference for research on the activities and clinical applications of lowmolecular-weight glycosaminoglycans. Other bioactiveties of low-molecular-weight chondroitin sulfate warrant further studies to maximize its potential benefits. Given the safety and nutritive content of lowmolecular-weight chondroitin sulfate, its applications as a functional food ingredient and food additive are also promising. Low-molecular-weight chondroitin sulfate can also be used as a natural anti-oxidant.

\section{Conclusion}

Low-molecular-weight chondroitin sulfate was firstly separated, purified and identified as disaccharide, tetrasaccharide and hexasaccharide, which showed higher anti-oxidant activity than chondroitin sulfate. This finding supported the potential application of lowmolecular-weight chondroitin sulfate as anti-oxidant and also displayed a beneficial way for the acidity oligosaccharide separation.

\section{Acknowledgement}

This project was financially supported by National Natural Science Foundation of China (Grant No. 31230057, 31401524), Natural Science Foundation of Jiangsu Province (BK20140143) and by Science and Technology of the Twelfth Five-Year Plan (2012BAD37B03).

\section{References}

Campo GM, Avenoso A, Campo S, D'Ascola A, Ferlazzo AM, Calatroni A. The anti-oxidant and antifibrogenic effects of the glycosaminoglycans hyaluronic acid and chondroitin-4sulphate in a subchronic rat model of carbon tetrachlorideinduced liver fibrogenesis. Chemico-Biolog Interact. 2004b; 148: 125-38.

Campo GM, Avenoso A, Campo S, D'Ascola A, Traina P, Calatroni A. Chondroitin-4-sulphate inhibits NF-kB translocation and caspase activation in collagen-induced arthritis in mice. Osteoarthr Cartilage. 2008; 16: 1474-83.

Campo GM, Avenoso A, Campo S, Ferlazzo AM, Calatroni, A. Administration of hyaluronic acid and chondroitin-4-sulfate limits endogenous anti-oxidant depletion and reduces cell damage in experimental acute pancreatitis. Pancreas 2004a; 28: E45-53.

Campo GM, Avenoso A, Campo S, Ferlazzo A, Altavilla D, Micali C, Calatroni A. Aromatic trap analysis of free radicals production in experimental collagen-induced arthritis in the rat: Protective effect of glycosaminoglycans treatment. Free Radical Res. 2003; 37: 257-68.

Choi J, Kim JK, Kim JH, Kweon DK, Lee JW. Degradation of hyaluronic acid powder by electron beam irradiation, gamma ray irradiation, microwave irradiation and thermal treatment: A comparative study. Carbohyd Polym. 2010; 79: 1080-85.

Dreher D, Junod AF. Role of oxygen free radicals in cancer development. Eur J Cancer. 1996; 32: 30-38.

Duh PD. Anti-oxidant activity of burdock (Arctium lappa Linne): Its scavenging effect on free-radical and active oxygen. J Americ Oil Chem Soc. 1998; 75: 455-61.

Egea J, García AG, Verges J, Montell E, López MG. Antioxidant, anti-inflammatory and neuroprotective actions of chondroitin sulfate and proteoglycans. Osteoarthr Cartilage. 2010; 18: S24-S27.

Jobe KL, Odman-Ghazi SO, Whalen MM, Vercruysse KP. Interleukin-12 release from macrophages by hyaluronan, chondroitin sulfate $\mathrm{A}$ and chondroitin sulfate $\mathrm{C}$ oligosaccharides. Immunol Lett. 2003; 89: 99-109.

Kim JK, Srinivasan P, Kim JH, Choi J, Park HJ, Byun MW, Lee, JW. Structural and anti-oxidant properties of gamma irradiated hyaluronic acid. Food Chem. 2008; 109: 763-70.

Liu W, Wang HY, Pang XB, Yao WB, Gao XD. Characterization and anti-oxidant activity of two low-molecular-weight polysaccharides purified from the fruiting bodies of Ganoderma lucidum. Int J Biol Macromol. 2010; 46: 451-57.

Mark MP, Baker JR, Kimata K, Ruch JV. Regulated changes in chondroitin sulfation during embryogenesis: An immunohistochemical approach. Int J Dev Biol. 1990; 34: 191-204.

McAlindon TE, LaValley MP, Gulin JP, Felson DT. Glucosamine and chondroitin for treatment of osteoarthritis: A systematic quality assessment and meta-analysis. JAMA. 2000; 283: 1469-75.

Nishino T, Aizu Y, Nagumo T. The influence of sulfate content and molecular weight of a fucan sulfate from the brown seaweed Ecklonia kurome on its antithrombin activity. Thromb Res. 1991; 64: 723-31.

Platzer M, Ozegowski JH, Neubert RHH. Quantification of hyaluronan in pharmaceutical formulations using high performance capillary electrophoresis and the modified uronic acid carbazole reaction. J Pharm Biomed Anal. 1999; 21: 491-96.

Pomin VH, Pereira MS, Valente AP, Tollefsen DM, Pav OMSG, Mour OPAS. Selective cleavage and anticoagulant activity of a sulfated fucan: Stereospecific removal of a 2-sulfate ester from the polysaccharide by mild acid hydrolysis, preparation of oligosaccharides, and heparin cofactor II- 
dependent anticoagulant activity. Glycobiology 2005; 15: 369 -81 .

Shimada K, Fujikawa K, Yahara K, Nakamura T. Antioxidative properties of xanthan on the autoxidation of soybean oil in cyclodextrin emulsion. J Agric Food Chem. 1992; 40: 945-48.

Stern R. Devising a pathway for hyaluronan catabolism: Are we there yet? Glycobiology 2003; 13: 105R-15R.

Trabucchi E, Pallotta S, Morini M, Corsi F, Franceschini R, Casiraghi A, Pravettoni A, Foschi D, Minghetti P. Low molecular weight hyaluronic acid prevents oxygen free radical damage to granulation tissue during wound healing. Int J Tissue React. 2002; 24: 65-71.

Trommer H, Wartewig S, Bottcher R, Poppl A, Hoentsch J,
Ozegowski JH, Neubert RHH. The effects of hyaluronan and its fragments on lipid models exposed to UV irradiation. Int J Pharm. 2003; 254: 223-34.

Valko M, Leibfritz D, Moncol J, Cronin MTD, Mazur M, Telser J. Free radicals and anti-oxidants in normal physiological functions and human disease. Int J Biochem Cell Biol. 2007; 39: 44-84.

Witvrouw M, De Clercq E. Sulfated polysaccharides extracted from sea algae as potential antiviral drugs. General Pharmacol. 1997; 29: 497-511.

Zhao H, Tanaka T, Mitlitski V, Heeter J, Balazs EA, Darzynkiewicz Z. Protective effect of hyaluronate on oxidative DNA damage in WI-38 and A549 cells. Int J Oncol. 2008; 32: 115967.

\footnotetext{
Author Info

I Jinpeng Wang (Principal contact)

I e-mail: jpwang1984@jiangnan.edu.cn
} 


\section{Your feedback about this paper}

1. Number of times you have read this paper 0

2. Quality of paper
Excellent
$\bigcirc$ Good
Moderate
Not good

3. Your comments 